có ý nghĩa thống kê $\mathrm{p}<0,001$.

Và thai phụ trong cuộc mổ lấy thai phải thêm phẫu thuật cắt tử cung có số chênh biến chứng vết mổ nông gấp 22,72 lần (KTC 95\%: 2,20 $235,26)$ những thai phụ không thêm phẫu thuật, thủ thuật, mối liên quan này có ý nghĩa thống kê $\mathrm{p}=0,009$.

Tuy nhiên, phân tích mô hình hồi quy đa biến, mối liên quan giữa biến chứng vết mổ nông và thời gian cuộc mổ, chuyển dạ kéo dài, tuổi thai.

\section{KẾT LUÂNN}

Nghiên cứu thực hiện 629 sản phụ và cho thây kết quả: tỷ lệ biến chứng vết mổ nông của nhóm không thay găng và của nhóm thay găng lần lượt là $7,8 \%$ và $2,6 \%$. Sự khác biệt của hai nhóm có ý nghĩa thống kê $\mathrm{p}=0,005$ (OR: 0,29; 95\%KTC: $0,13-0,68)$.

Các yếu tố liên quan đến biến chứng vết mổ nông: ối võ có số chênh biến chứng vết mổ nông gấp 3,27 lần (KTC 95\%: 11,56-6,85) với $p=$ 0,002 , thời gian từ lúc nhập viện đến lúc mổ từ 12 - 24 giờ làm tăng biến chứng vết mổ nông gấp 5,54 lần (KTC 95\%: 1,11 - 27,7) với $\mathrm{p}=$ 0,037 , thai phụ trong cuộc mổ lấy thai phải thêm phẫu thuật cắt tử cung có số chênh biến chứng vết mổ nông gấp 22,72 lần (KTC 95\%: 2,20 $235,26)$ với $p=0,009$.C

\section{KIẾN NGH!}

Cập nhật thay găng trước khi đóng bụng vào trong Quy trình phẫu thuật mổ lấy thai. Tuy nhiên, thay găng chì là 1 biện pháp giảm nhiễm khuẩn vết mổ, bên cạnh biện pháp khác như: giảm thời gian mổ lấy thai, giảm lượng máu mất. Cần tuân thủ các quy trình chăm sóc bệnh nhân đảm bảo an toàn phẩu thuật cho các trường hợp phẫu thuật, đặc biệt lưu ý ở đối tượng vỡ ối, ASA cao, mổ lấy thai có phẫu thuật cắt tử cung kèm theo.Cần có thêm nghiên cứu đánh giá hiệu quả thay găng trước khi đóng bụng trong phẫu thuật phụ khoa, nghiên cứu đánh giá hiệu quả kinh tế của thay găng khi giảm tỷ lệ nhiếm khuẩn vết mổ, nghiên cứu đề cập bằng chứng vi sinh về nguồn vây nhiễm từ bàn tay phẫu thuật viên.

\section{TÀI LIỆU THAM KHẢO}

1. Nguyễn Quỳnh Chi (2015), "Khảo Sát Các Yếu Tố Nguy Cớ Liên Quan Đến Tình Trạng Vết Mồ Thành Bụng Trên Sản Phụ Mổ Lấy Thai Tại Bệnh Viên Từ 'ंũ".

2. Vũ Hương Huyền (2019), "Khảo Sát Tình Trang Lành Vết Mổ Thành Bung Trên Sản Phu Mổ Lẫy Thai Theo Thang Diểm Asepsis Tại Bệnh Viện Hùng Vương"

3. Md1 Jonathan D. Scrafford, Buvana Reddy, Md2, Colleen Rivard, Md1, And Rachel I. Vogel, Ph.D1 (2018), "Effect Of Intra-Operative Glove-Changing During Cesarean Section On PostOperative Complications: A Randomized Controlled Trial". Arch Gynecol Obstet, 296 (6), 1449-1454.

4. M. A. Olsen, Denise M. Butler Am Fau Willers, Preetishma Willers Dm Fau - Devkota, Gilad A. Devkota P Fau - Gross, Victoria J. Gross Ga Fau - Fraser ,V. J. Fraser Risk Factors For Surgical Site Infection After Low Transverse Cesarean Section". (0899-823x (Print)).

\title{
ĐĂC ĐIỂM LÂM SÀNG VÀ MỨC Độ NĂNG CỦA TỔN THƯƠNG PHỔI TRÊN X QUANG NGỰC Ở BÊ̂NH NHẦN NHẬP VIỆN DO COVID-19
}

\author{
Hoàng Văn Sỹ ${ }^{1}$, Nguyễn Minh Kha ${ }^{1}$, Nguyễn Thanh Phong ${ }^{2}$, \\ Huỳnh Nghĩa ${ }^{1}$, Lê Phước Truyền ${ }^{1}$, Triệu Khánh Vinh ${ }^{1}$, Đào Thị Thu Hiền ${ }^{1}$, \\ Lê Thế Đức Tài ${ }^{1}$, Trần Thanh Tòng ${ }^{1}$, Phan Văn Hiếu ${ }^{1}$, \\ Bùi Nguyễn Thùy Trang', Lê Minh Quân ${ }^{1}$, Trần Minh Đương', \\ Nguyễn Đình Thắng ${ }^{1}$, Nguyễn Nhật Tài ${ }^{1}$, Vương Thị Ngọc Lan ${ }^{1}$ \\ học đơn giản giúp chẩn đoán độ nặng và tiên lượng \\ phù hợp trong quản lý bệnh COVID-19. Dữ liệu vể \\ đánh giá độ nặng tổn thương phổi trên $X$ quang ở \\ bệnh nhân COVID-19 tại Việt Nam còn hạn chế. Mục \\ tiều: Nghiên cứu này được tiến hành để mô tả đặc \\ điểm lâm sàng, mức độ nặng tổn thương phổi trên $X$ \\ quang ngực ở bệnh nhẩn COVID-19 và đánh giá mối \\ liên quan giữa những yếu tố lâm sàng với độ nặng của \\ tổn thương phổi trên $X$ quang ngực. Đối tượng và \\ phương pháp nghiên cứu: Nghiền cứu hồi cứu trên \\ bệnh nhân nhiễm COVID-19 nhập viện trong khoảng \\ thời gian từ ngày 30/08/2021 đến ngày 30/09/2021. \\ Đánh giá mức độ nặng của tổn thương phổi trên $X$
}

\section{TÓM TẮT}

Mở đâu: COVID-19 đã và đang trở thành gánh nặng y tế toàn câu. $X$ quang ngực là công cụ hình ảnh

\footnotetext{
${ }^{1}$ Dại học Y Dượ TP. Hồ Chí Minh

²Bệnh viện Bệnh Nhiệt đới TP. Hồ Chí Minh

Chịu trách nhiệm chính: Hoàng Văn Sỹ

Email: hoangvansy@ump.edu.vn

Ngày nhận bài: 12.8.2021

Ngày phản biện khoa học: 5.10.2021

Ngày duyệt bài: 15.10 .2021
} 
quang ngực trong 24 giờ đầu nhập viện bằng thang điểm Brixia. Kết quả: Nghiên cứu có 279 bệnh nhân với $57,7 \%$ giới nữ, tuổi trung bình $59,6 \pm 13,9$ và $72,4 \%$ bệnh nhân COVID-19 nhập viện có bệnh nền. Điểm Brixia có giá trị trung vị là $13(9-16)$ điểm. Phổi phải và phổi trái có điểm Brixia lần lượt $7(5-9)$ và 6 $(4-8)$. Vùng thấp của phổi có điểm tổn thương cao hơn so với vùng giữa và trên của phổi. Bệnh nhân thuộc nhóm có điểm Brixia cao có nhịp tim nhanh hơn, BMI cao, điểm NEW2 cao hơn so với nhóm có điểm Brixia thấp $(p<0,05)$. Tỷ lệ cao thở oxy mask ở nhóm có điểm Brixia thấp là $39,6 \%$, trong khi đó tỷ lệ này là $62,4 \%$ ở nhóm có điểm số Brixia cao. Kết luân: Nghiên cứu cho thấy bệnh nhân COVID-19 nhập viện có độ tuổi cao tuổi, với giới nữ chiếm ưu thế và phẩn lớn bệnh nhân có bệnh nền. Điểm Brixia trong nghiên cứu là cao. Bệnh nhân có điểm Brixia càng cao, tỷ lệ cần hỗ trợ bằng các dụng cụ cung cấp oxy càng cao.

Tư khóa:. COVID-19, tổn thương phổi, X quang ngực

\section{SUMMARY \\ CLINICAL CHARACTERISTICS AND A SEVERITY SCORE OF LUNG INJURY ON CHEST RADIOGRAPHY IN HOSPITALIZED PATIENTS WITH COVID-19}

Introduction: COVID-19 has become a global health burden. Chest radiograph is a simple imaging tool to help diagnose severity and appropriate prognosis in the management of COVID-19 disease. There are limited data on the assessment of lung injury severity on chest X-rays in COVID-19 patients in Vietnam. Objective: This study was conducted to describe the clinical characteristics, the severity of lung injury on chest X-rays in hospitalized patients with COVID-19, and to evaluate the relationship between clinical factors and the severity score of lung involvement on chest X-rays. Methods: A retrospective study on hospitalized patients with COVID-19 between August 30, 2021, and September 30,2021 . Assessing the severity score of lung injury on chest X-rays in the first 24 hours of admission using the Brixia score. Results: A total of 279 patients, with $57.7 \%$ females and median age 56.1 years, were included in this study, $72.4 \%$ of hospitalized COVID-19 patients had underlying disease. The median Brixia score was $13(9-16)$ points. The right lung and the left lung had a Brixia score of 7 (5-9) and 6 (4-8), respectively. Patients in the group with a high Brixia score had faster heart rate, higher BMI, and higher NEW2 score than the group with a low Brixia score $(p<0.05)$. The high rate of oxygen mask breathing in the group with a low Brixia score was $39.6 \%$, this rate was $62.4 \%$ in the group with a high Brixia score. Conclusion: The study revealed that hospitalized COVID-19 patients were elderly, with female predominance, and the majority of patients had underlying medical conditions. In the study, the median Brixia score was high. The higher the patient's Brixia score, the higher the odds of needing assistance with oxygen delivery devices.

Keywords: COVID-19, lung injury, chest X-ray.

\section{I. ĐĂT VẤN ĐỀ}

Bệnh do Coronavirus năm 2019 (COVID-19) gây hội chứng nguy kịch hô hấp cấp, có số người nhiễm bệnh và tử vong cao trên toàn thế giới. Đến tháng 3 năm 2020, Tổ chức Y tế Thế giới WHO tuyên bố đây là đại dịch toàn cầu. Tại Việt Nam, làn sóng thứ tư của đại dịch này đắc biệt với biến chủng Delta đã gây ra những tổn thất nặng nề về nhiều mặt. Mặc dù, phân lớn bệnh nhân có biểu hiện nhẹ hoặc không biến chứng, nhưng có đến $15 \%$ các bệnh nhân có thể tiến triển nặng, cần nhập viện kèm hỗ trợ oxy và lên đến $5 \%$ bệnh nhân cần nhập vào đởn vị hồi sức tích cưc [1].

Mức độ nặng của bệnh lý nhu mô phổi được xem là một yếu tố nguy cơ tiềm ẩn liên quan kết cưc tử vong; bác sĩ nên nhân thức được điều này để cải thiên sư phân tầng nguy cơ và điều chỉnh cường độ chăm sóc cho những bệnh nhân có nguy cơ cao [2]. Chụp cắt lớp vi tính lồng ngực là phương tiên hình ảnh hoc có độ nhạy và độ chuyên cao trong việc chẩn đoán, đánh giá mức độ tổn thương phổi và theo dõi diễn tiến ở bệnh nhân COVID-19, tuy nhiên công cụ này đòi hỏi trang bị kỹ thuật phức tạp và không phù hợp để áp dụng ở nhiều bệnh viện dã chiến. $X$ quang ngực được chứng minh có thể thay thế cho chụp cắt lớp vi tính để đánh giá mức độ nặng của bệnh lý nhu mô, đặc biệt trong việc theo dõi sứ tiến triển nhanh chóng của các tổn thương phổi do COVID-19 [3].

Hầu hết các nghiên cứu cho thấy X-quang ngực có độ nhạy và độ đặc hiệu không cao trong việc chẩn đoán trên bệnh nhân COVID-19 [3]. Tuy nhiên, $X$ quang ngực là một phương tiện hình ảnh học đơn giản, rẻ tiền, nhanh chóng, an toàn, có tính lặp lại cao, sẵn có tại nhiều cơ sở y tế và đây cũng là một công cụ mà các nhà lâm sàng không chuyên trong lînh vực hình ảnh học cũng có thể dễ dàng sử dụng. Nhiều nghiên cứu trên thế giới đưa ra cách phân loại mức độ nặng của các tổn thương phổi trên $X$ quang ngực trên bệnh nhân COVID-19, và cho thây vai trò tiên lượng kết cục ở bệnh nhân COVID-19 [3], [4]. Borghesi và cộng sự đánh giá $X$ quang của 100 bệnh nhân COVID-19 người Ý, tác giả này đã đề xuất thang điểm về phân loại mức độ nặng của tổn thương phổi trên $X$ quang ngực mang tên Brixia. Kết quả của nghiên cứu cũng chỉ ra rằng nhóm bệnh nhân tử vong thì có điểm Brixia cao hơn có ý nghĩa thống kê so với nhóm xuất viện [5]. Tuy nhiên, hiện nay vẫn chưa có đồng thuận thống nhất để đánh giá mức độ nặng của tổn thương phổi trên $X$ quang. Tại Việt Nam, các báo 
cáo, nghiên cứu về đặc điểm tổn thương phổi do COVID-19 trên $X$ quang ngực vẫn còn hạn chế.

Do đó chúng tôi tiến hành nghiên cứu này với mục tiêu mô tả đặc điểm lâm sàng và mức độ nặng của tổn thương phổi trên $X$ quang ngực ở bệnh nhân COVID-19 nhập viện qua thang điểm Brixia. Đồng thời, chúng tôi cũng đánh giá mối liên quan giữa những yếu tố lâm sàng với độ nặng của tổn thương phổi trên X-quang ngực.

\section{II. ĐỐI TƯợ̂nG VÀ PHƯƠNG PHÁP NGHIÊN CỨU}

Đây là nghiên cứu hồi cứu dựa vào thông tin từ hồ sơ bệnh án những bệnh nhân COVID-19 nhập bệnh viện dã chiến điều trị COVID-19 Quận 8 số 1 trong thời gian từ 01/09/2021 đến ngày 30/09/2021. Bệnh nhân được chẩn đoán xác định nhiễm SARS-COV-2 dựa vào kết quả Realtime PCR dịch mũi hầu. Nghiên cứu loại trừ những trường hợp bệnh nhân dưới 18 tuổi, có tiền sử lao phổi, viêm phổi, ung thư phổi trước đây.

Thông số lâm sàng được thu thập bao gồm các đặc điểm về nhân trắc học như độ tuổi, giới, tiền căn bệnh lý nền, tình trạng tiêm ngừa vắcxin, các chỉ số lâm sàng, cận lâm sàng và dụng cụ hỗ trợ oxy lúc bệnh nhân nhập viện. Bệnh lý nền dựa theo chẩn đoán đã có trước đây của bệnh nhân.

Đánh giá mức độ nặng của tổn thương phổi trên $X$ quang dựa vào theo thang điểm Brixia [5]. Thang điểm Brixia được đánh giá độc lập bởi 2 bác sĩ nội trú gồm 1 nội trú nội và 1 nội trú huyết học năm 2, nếu có sự khác biệt về điểm số sẽ có thêm bác sĩ thứ 3 là giảng viên Nội tổng quát kiểm tra và thống nhất. Điểm số mức độ nặng Brixia chia phổi thành 6 vùng trên Xquang ngực thẳng: (i) vùng trên (I và IV): phía trên bờ dưới quai động mạch chủ (aortic arch), (ii) vùng giữa (II và V): phía dưới bờ dưới quai động mạch chủ và phía trên bờ dưới tĩnh mạch phổi dưới bên phải (tức là cấu trúc rốn phổi-hilar), và (iii) vùng dưới (III và VI): phía dưới bờ dưới tĩnh mạch phổi dưới bên phải (tức là đáy phổi- lung bases) ( Hình 2). Điểm (từ 0 đến 3 ) được tính cho mỗi vùng dựa trên các tổn thương phổi được phát hiện trên $X$ quang ngực thẳng, như sau: Điểm 0 - không có tổn thướng phổi; Điểm 1 thâm nhiếm mô kẽ; Điểm 2 - thâm nhiễm mô kẽ và phế nang (ưu thế mô kẽ); Điểm 3 - thâm nhiếm mô kẽ và phế nang (ưu thế phế nang). Điểm số của 6 vùng phổi được cộng lại để có điểm độ nặng trên $X$ quang tổng điểm nằm trong khoảng từ 0 đến 18 điểm. Các đặc điểm $X$ quang ngực khác (như tràn dịch màng phổi, lớn mạch máu phổi) không được đưa vào hệ thống tính điểm.
Xử lý thống kê. Dữ liệu được được nhập và xử lý theo phần mềm Stata 13 (StataCorp. 2013. Stata Statistical Software: Release 13. College Station, TX: StataCorp LP). Biến liên tục được thể hiện dưới dạng trung bình \pm độ lệch chuẩn (nếu phân phối chuẩn), dưới dạng trung vị̣, khoảng tứ phân vị (nếu không có phân phối chuẩn). Biến danh định được thể hiện dưới dạng phần trăm. Dân số trong nghiên cứu được chia thành 2 nhóm dựa vào giá trị trung vị của thang điểm Brixia. So sánh sự khác biệt giữa 2 nhóm dùng phép kiểm Student $t$ test hoặc Chi bình phương).

\section{KẾT QUẢ NGHIÊN CỨU}

Trong thời gian nghiên cứu, chúng tôi thu thập được 279 bệnh nhân thỏa điều kiện nhận vào nghiên cứu. Độ tuổi trung bình ghi nhận được là $59,6 \pm 13,9$ tuổi, giới nữ có 161 bệnh nhân, chiếm $57,7 \%$. Đa phần bệnh nhân nhập viện có bênh nền với tỷ lệ là 72,4\% (202/279), trong đó 2 bệnh lý nền chiếm tỷ lệ cao nhất đó là tăng huyết áp và đái tháo đường với tỷ lệ lần lượt là $53,1 \%$ và $23,7 \%$. Kết quả nghiên cứu cũng ghi nhận, giá trị BMI là $24,5 \pm 3,4 \mathrm{~kg} / \mathrm{m}^{2}$, với $8,2 \%$ bệnh nhân béo phì theo tiêu chuẩn người châu Á. Tỷ lệ bệnh nhân có hút thuốc lá là $29,4 \%$.

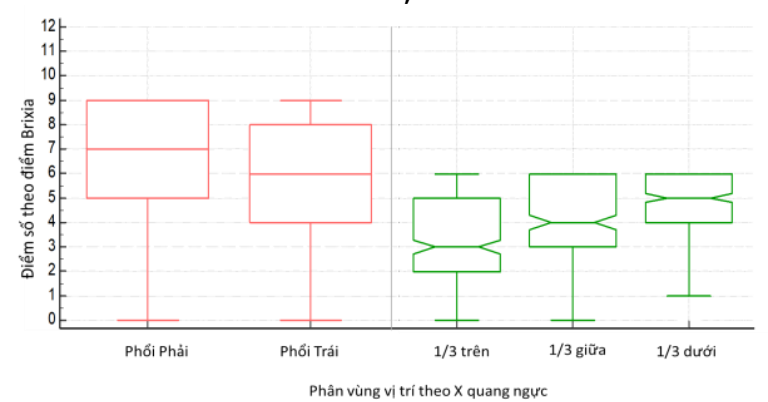

Biêu đồ 1. Điểm số tổn thương phổi trên X quang ngực phân theo vùng

Khi đánh giá tổn thương phổi bằng thang điểm Brixia, chúng tôi ghi nhận điểm Brixia của bệnh nhân trong nghiên cứu không có phân phối chuẩn với giá trị trung vị 13 điểm, khoảng tứ phân vị: $9-16$ điểm. Phổi phải có điểm số tổn thương trên $X$ quang là $7(5-9)$ điểm lớn hơn so với phổi trái với điểm số tổn thương trên $X$ quang là $6(4-8)$ điểm. Biểu đồ 1 thể hiện điểm số tổn thương trên $X$ quang phân theo vùng dựa trên thang điểm Brixia. Vùng $1 / 3$ dưới phổi có điểm số tổn thương nặng nhất với giá trị 5 (4 $6)$, kế đến là vùng $1 / 3$ giữa với điểm tổn thương là $4(3-6)$. Vùng $1 / 3$ trên có điểm số tổn thương thấp nhất với giá trị $3(2-5)$.

Chúng tôi chia dân số nghiên cứu thành 2 
nhóm dựa theo giá trị trung vị của thang điểm Brixia. Theo đó, nhóm điểm Brixia thấp gồm những bệnh nhân có điểm số Brixia < 13 điểm, bênh nhân còn lại thuộc nhóm điểm Brixia cao. Đặc điểm nhân trắc học và lâm sàng giữa 2 nhóm được trình bày ở Bảng 1.

Bảng 1. Đặc điểm nhân trắc và lâm sàng phân theo nhóm điểm Brixia

\begin{tabular}{|c|c|c|c|c|}
\hline Biến số & $\begin{array}{c}\text { Tống } \\
\mathbf{N = \mathbf { 2 7 9 }}\end{array}$ & $\begin{array}{c}\text { Nhóm Brixia thấp } \\
\mathbf{n = 1 3 8}\end{array}$ & $\begin{array}{c}\text { Nhóm Brixia cao } \\
\mathbf{n = 1 4 1}\end{array}$ & Giá trị P \\
\hline Tuối, năm & $59,6 \pm 13,9$ & $59,8 \pm 15,5$ & $59,6 \pm 12,0$ & 0,89 \\
\hline Giới nữ', $\mathrm{n}(\%)$ & $161(57,7)$ & $72(52,2)$ & $89(63,1)$ & 0,06 \\
\hline Đã tiêm vắc xin, $\mathrm{n}(\%)$ & $134(48,0)$ & $64(46,4)$ & $70(49,7)$ & 0,59 \\
\hline Tăng huyết áp, $\mathrm{n}(\%)$ & $148(53,1)$ & $71(51,5)$ & $77(54,6)$ & 0,60 \\
\hline Đái tháo đường 2, $\mathrm{n}(\%)$ & $66(23,7)$ & $37(26,8)$ & $29(20,6)$ & 0,22 \\
\hline Hút thuốc lá, $\mathrm{n}(\%)$ & $82(29,4)$ & $49(35,5)$ & $33(23,4)$ & 0,03 \\
\hline Béo phì, $\mathrm{n}(\%)$ & $126(45,2)$ & $49(35,5)$ & $77(54,6)$ & 0,001 \\
\hline HA tâm thu, mmHg & $130,4 \pm 19,1$ & $131,4 \pm 18,1$ & $129,5 \pm 20,0$ & 0,41 \\
\hline Mạch, lần/phút & $96,2 \pm 15,9$ & $98,1 \pm 15,8$ & $94,2 \pm 15,2$ & 0,04 \\
\hline Tần số thở, lần/phút & $29,7 \pm 13,1$ & $29,3 \pm 17,7$ & $30,0 \pm 6,0$ & 0,69 \\
\hline BMI, Kg/m² & $24,5 \pm 3,4$ & $25,2 \pm 3,3$ & $23,9 \pm 3,4$ & 0,001 \\
\hline Điếm NEWS 2 & $8,1 \pm 2,9$ & $8,7 \pm 7,4$ & $7,4 \pm 3,5$ & $<0,001$ \\
\hline
\end{tabular}

Giá trị được thể hiện dưới dạng trung bình \pm độ lệch chuẩn, số lượng (phần trăm)

Về phương tiên hỗ trợ oxy tai thời điểm nhập viện, chúng tôi ghi nhận tỷ lệ thở HFNC; oxy mask; oxy cannula và khí trời lẩn lượt là 10,8\%; $51,6 \% ; 28,3 \%$ và $9,3 \%$. Biểu đồ 2 cho thây tỷ lệ các dụng cụ cung cấp oxy cho bệnh nhân theo nhóm điểm Brixia. Ở nhóm bệnh nhân có điểm Brixia thấp, tỷ lệ bệnh nhân sử dụng cannula cũng như thở khí trời cao hơn so với nhóm có điểm Brixia cao. Ngược lại ở nhóm bệnh nhân có điểm Brixia cao, tỷ lệ bệnh nhân cần hỗ trợ oxy bằng mask hoặc HFNC chiếm cao hơn, sự khác biệt về tỷ lệ này giữa 2 nhóm có ý nghĩa thống kề với chỉ số $p<0,001$ với phép kiểm Chi bình phương.

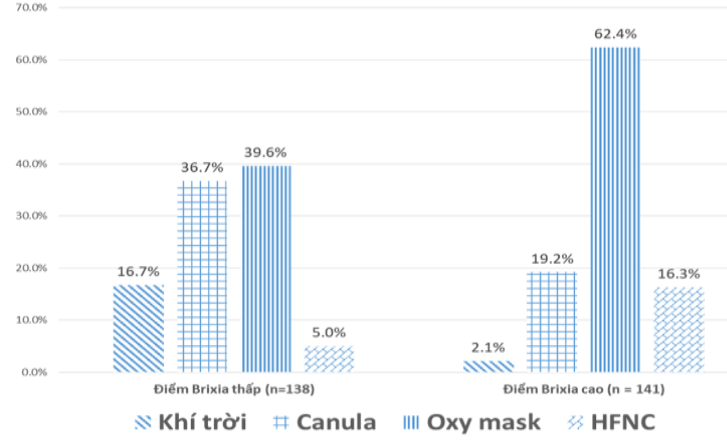

Biểu đồ 2. Tỷ lệ các phương tiện cung cấp oxy theo nhóm điêm Brixia

\section{BÀN LUÂN}

COVID-19 là một đại dịch ảnh hưởng to lớn trên toàn cầu trong mọi lĩnh vực và vai trò của $X$ quang ngực trong việc quản lý và tiên lượng là rất quan trọng, đặc biệt trong tình huống có sự không tương xứng giứa lâm sàng và tình trạng tổn thương phổi và sự không sẵn có của chụp cắt lớp vi tính ngực. Vấn đề mô tả các đặc điểm về dịch tễ học, lâm sàng, mức độ tổn thương phổi trên $X$ quang ngực nhằm có cái nhìn khái quát về mối liên quan giữa các đặc điểm này, từ đó có kế hoach chăm sóc, theo dõi và xử trí nhằm cải thiển tử vong cho bênh nhân COVID19, đặc biệt khi có sự khác biệt nhân trắc học đặc trưng ở dân số Châu Á và Việt Nam. Chúng tôi thực hiện nghiên cứu này nhằm mô tả đặc điểm lâm sàng và mức độ tổn thương phổi của bệnh nhân nhiềm COVID-19 tại Việt Nam.

Chúng tôi ghi nhận tuổi trung bình của các bênh nhân là 59,6 $6 \pm 13,9$, cao hơn so với nghiên cứu của tác giả Setiawati và cộng sự là $53 \pm 13$ [6], thấp hơn so với nghiên cứu của tác giả Reeves và cộng sự là $65 \pm 16$ [7]. Nghiên cứu của chúng tồi cũng ghi nhận tỉ lệ nữ nhập viện cao hơn nam với $57,7 \%$ ở nữ so với $42,3 \%$ ở nam, khác biệt so với các nghiên cứu khác thì có tỉ lệ nam cao hơn nữ (tỉ lệ nam trong nghiên cứu của tác giả Setiawati và cộng sự là $51,1 \%[6]$; của tác giả Reeves và cộng sự là 59,2\% [7], của tác giả Schalekamp và cộng sự là 66,6\% [8]). Đồng thời, tỉ lệ giới nữ trong nghiên cứu của chúng tôi của nhóm có thang điểm Brixia cao ( $\geq 13$ điểm) cao hơn nhóm có thang điểm Brixia thấp ( $<13$ điểm) với $p=0,06$.

Về bệnh đồng mắc, chúng tôi ghi nhận phần lớn bệnh nhân nhiếm COVID-19 nhập viện thường kèm theo bênh nền với tỉ lẹ $72,4 \%$ và trong đó thì bệnh nền thường gặp nhất là tăng huyết áp chiếm $53,1 \%$, kễ tiếp là đái tháo đường týp 2 với $23,7 \%$. Kết quả này tương đồng với nghiên cứu của tác giả Schalekamp và cộng sự 
với tỉ lệ bệnh nhân có bệnh đồng mắc là 71,3\% và tî lệ tăng huyết áp cũ̃ng chiếm cao nhất với $52,4 \%$ số bệnh nhân có bệnh đồng mắc [8]. Nhưng chúng tôi ghi nhận sự khác biệt so với nghiên cứu của tác giả Setiawati và cộng sự ghi nhận số bệnh nhân có bệnh nền chỉ chiếm $48,9 \%$ và đái tháo đường lại là bệnh đồng mắc thường gặp nhất $(7,6 \%)$ [6]. Bên cạnh đó, chúng tôi cũng ghi nhận tỉ lệ bệnh nhân có hút thuốc lá là 29,4\% cao hơn 3 lần kết quả nghiên cứu của tác giả Reeves và cộng sự $(8,8 \%)$ [7]. Các bệnh nhân nhập viện theo nghiên cứu của chúng tôi ghi nhận được có xu hướng béo phì tương đối cao với tỉ lệ 45,2\% tổng số bệnh nhân theo tiêu chuẩn của người Châu Á, cao hơn so với nghiên cứu của tác giả Setiawati và cộng sự có tỉ lệ béo phì là 4/225 (1,8\%) [6].

Điểm trung vị của thang điểm Brixia theo nghiên cứu của chúng tôi là 13 điểm, cao hơn so với nghiên cứu gốc xuất phát nguồn của thang điểm Brixia với điểm số trung vị sau khi được đánh giá lại bởi các nhà hình ảnh học lồng ngực là 7 [5]. Một vài đặc điểm cũng được chúng tôi ghi nhận khác biệt có ý nghĩa thống kê giữa nhóm có điểm Brixia cao và thấp là: (1) tî lệ bệnh nhân hút thuốc lá ở nhóm có điểm Brixia cao thì nhỏ hơn nhóm có điểm Brixia thấp với $23,4 \%$ so với $35,5 \%$ (2) tỉ lệ béo phì ở nhóm có điểm Brixia cao thì lớn hơn so với nhóm có điểm Brixia thấp, (3) số trung bình BMI ở nhóm có điểm Brixia cao là $25,2 \pm 3,3$ lớn hơn so với nhóm có điểm Brixia thấp là $23,9 \pm 3,4$, (4) tần số mạch trung bình ghi nhận được ở nhóm có điểm Brixia cao là $94,2 \pm 15,2$ thì thấp hơn nhóm có điểm Brixia thấp với $98,1 \pm 15,8$, và (5) điểm số NEWS 2 ở nhóm có điểm Brixia cao nhỏ hơn nhóm có điểm Brixia thấp với điểm trung bình lần lượt là $7,4 \pm 3,5$ và $8,7 \pm 7,4$.

Về điểm số tổn thương phổi, chúng tôi cũng ghi nhận được phổi phải có số điểm tổn thương cao hớn phổi trái và số điểm tổn thương thấp dần từ dưới đi lên khi phân mỗi phổi làm 3 vùng với vùng dưới cao hơn vùng giữa, vùng giữa cao hơn vùng trên. So sánh với nghiên cứu của tác giả Schalekamp và cộng sự, họ ghi nhận tổn thương mức độ nặng (chiếm $>50 \%$ của phân nửa phổi một bên) ở bên trái chiếm 132/356 trường hợp $(37,1 \%)$ và ở bên phải chiếm $118 / 356$ trường hợp $(33,1 \%)$ [8]. Bên cạnh đó, họ cũng ghi nhận được rằng tổn thương phổi do COVID-19 thì có xu hướng phân bố ở phần thấp của phổi so với phần cao và phần thấp có tổn thương nặng hơn phần cao, tương tự nghiên cứu của chúng tôi, với tổn thương nửa dưới phổi trái và phải lần lượt là 312/356 trường hợp (số trường hợp tổn thương nặng là 102) và 305/356 trường hợp (số trường hợp tổn thương nặng là 69), với với tổn thương nửa trên phổi trái và phải lần lượt là 239/356 trường hợp (số trường hợp tổn thương nặng là 30) và 246/356 trường hợp (số trường hợp tổn thương nặng là 49) [8].

Chúng tôi cũng ghi nhận được sự liên quan giữa nhu cầu sử dụng liệu pháp oxy ở nhóm bệnh nhân có điểm Brixia cao và thấp. Trong đó, nhóm có điểm Brixia cao thì có nhu cầu hố trợ oxy với các liệu pháp nâng cao hơn (oxy mask, HFNC) so với nhóm có điểm Brixia thấp với sự ưu thế của nhóm bệnh nhân cần hỗ trợ oxy cannula và không cần thở oxy. Điều này cũng được ghi nhận trong nghiên cứu của tác giả Reeves và cộng sự là nhóm có điểm tổn thương phổi trong thang điểm X-quang ngực của họ cao hơn thì có nhu câuu thở oxy cao hơn với thở oxy qua cannula (43/78 trường hợp - 55,1\%) và đặt nội khí quản (18/78 trường hợp - 23,1\%) so với nhóm có điểm tổn thương phổi thấp hơn với thở oxy cannula là $67 / 162$ trường hợp $(41,4 \%)$ và đặt nội khí quản là $6 / 162$ trường hợp $(3,7 \%)$; bển cạnh đó, nhóm có số điểm thẩp X-quang ngực có số bệnh nhân thở khí trời $(89 / 162$ trường hợp - 54,9\%) cao hơn so với nhóm có số điểm X-quang ngực cao với số trường hợp thở khí trời là $17 / 78$ trường hợp (21,8\%) [7]. Điều này chỉ ra sự tương thích trong việc đánh giá các bệnh nhân có tổn thương phổi càng nhiều thì nhu câu cần hỗ trợ oxy càng cao.

Hạn chế của nghiên cứu. Bên cạnh đó, nghiên cứu của chúng tôi thực hiện là nghiên cứu hồi cứu, mô tả các thông tin dựa trên hồ sơ bệnh án sẽ không tránh khỏi sai lệch thông tin qua việc khai thác bệnh sử, triệu chứng cơ năng và thực thể. Thang điểm Brixia khá phức tạp trong việc đánh giá tổn thương phổi, đòi hỏi một nhà hình ảnh học đã được tập huấn để phân tích điểm số chính xác, đặc biệt với điều kiện thiếu hụt về nhân lực trong đại dịch COVID-19.

\section{KẾT LUẬN}

Nghiên cứu đem lại những dữ liệu đầu tiên trên đă̆c điểm các bệnh nhân nhiếm COVID-19 với tuổi trung niên đến cao tuổi, giới nữ chiếm ưu thễ, đa số là có kèm bệnh nền và bệnh nền nhiều nhất là tăng huyết áp. Phổi phải có điểm tổn thương cao hơn phổi trái. Vùng thấp của phổi có điểm tổn thương cao hơn so với vùng giữa và trên của phổi. Bệnh nhân thuộc nhóm có điểm Brixia cao thường có nhịp tim nhanh hơn, BMI cao, điểm NEW2 cao hơn so với nhóm có 
điểm Brixia thấp. Bệnh nhân có điểm Brixia càng cao thì càng có nhu cầu cần hỗ trợ oxy bởi các thiết bị cung cấp oxy.

\section{TÀI LIÊU THAM KHẢO}

1. Schaefer-Prokop C, Prokop M. Chest Radiography in COVID-19: No Role in Asymptomatic and Oligosymptomatic Disease. Radiology. 2021;298(3):E156-e7.

2. Akl EA, Blažić I, Yaacoub S, et al. Use of Chest Imaging in the Diagnosis and Management of COVID-19: A WHO Rapid Advice Guide. Radiology. 2021:298(2):E63-e9.

3. Martínez Chamorro $E$, Díez Tascón A, Ibáñez Sanz L, et al. Radiologic diagnosis of patients with COVID-19. Radiologia (Engl Ed). 2021;63(1):56-73.

4. Au-Yong I, Higashi $Y$, Giannotti $E$, et al. Chest Radiograph Scoring Alone or Combined with Other Risk Scores for Predicting Outcomes in COVID-19.
Radiology. 2021:210986

5. Borghesi A, Maroldi R. COVID-19 outbreak in Italy: experimental chest X-ray scoring system for quantifying and monitoring disease progression. La radiologia medica. 2020;125(5):509-13.

6. Setiawati $R$, Widyoningroem $A$, Handarini $T$, et al. Modified Chest X-Ray Scoring System in Evaluating Severity of COVID-19 Patient in Dr. Soetomo General Hospital Surabaya, Indonesia. Int J Gen Med. 2021;14:2407-12.

7. Reeves RA, Pomeranz C, Gomella AA, et al. Performance of a Severity Score on Admission Chest Radiography in Predicting Clinical Outcomes in Hospitalized Patients With Coronavirus Disease (COVID-19). AJR Am J Roentgenol. 2021;217(3):623-32.

8. Schalekamp $S$, Huisman $M$, van Dijk RA, et al. Model-based Prediction of Critical Illness in Hospitalized Patients with COVID-19. Radiology. 2021;298(1):E46-e54.

\section{NHÂ̂N XÉT KẾT QUẢ NộI SOI U BUỒNG TRÚNG TẠI BỆNH VIỆN PHỤ SẢN THÁI BÌNH NĂM 2010 VÀ NĂM 2020}

\section{TÓM TẮT}

Mục tiêu: Nhân xét kết quả nội soi xử trí u buồng trứng tai Bệnh viển Phu Sản Thái Bình năm 2010 và năm 2020. Đối tượng và phương pháp nghiên cứu: Hồi cứu bênh án tất cả số bênh nhân có chẩn đoán lâm sàng là u buồng trứng trong 2 giai đoạn: từ $1 / 1 / 2010$ đến $31 / 12 / 2010$ và từ $1 / 1 / 2020$ đến $31 / 12 / 2020$, đã được phẫu thuật nội soi và có chẩn đoán mô bệnh học là u buồng trứng tại Bệnh viện Phụ Sản Thái Bình. Kết quả: Tỷ lệ phẫu thuật nội soi u buồng trứng năm $2020(71.2 \%)$ cao hơn hẳn so với năm 2010 (33,3\%), với p<0,05. Năm 2010, u thanh dịch chiếm tỷ lệ cao nhất là $46,7 \%$. Năm 2020 , u bì chiếm tỷ lệ cao nhất là 39,7\%. Năm 2010, tỷ lệ cắt buồng trứng là cao nhất ở các nhóm kích thước u $<50 \mathrm{~mm}$ và $50-100 \mathrm{~mm}$. Năm 2020 tỷ lệ bóc u là cao nhất ở các nhóm kích thước u $<50 \mathrm{~mm}$ và $50-100 \mathrm{~mm}$, lần lượt chiếm tỷ lệ $89,8 \%$ và $68,4 \%$; nhóm kích thước $>100 \mathrm{~mm}$ tỷ lệ bóc u là $25,0 \%$. Thời gian phấu thuật năm 2020 ở mức độ không dính và dính ít giảm hơn so với năm 2010. Tai biến và biến chứng trong và sau phẫu thuâtt năm 2020 không có trường hợp nào. Kết luận: U buồng trứng là một trong những vấn đề hay gặp nhất trong lĩnh vực phụ khoa. Phẫu thuật nội soi ngày càng được ứng dụng rộng rãi trong xử trí u buồng trứng, đem lại lợi ích cho bệnh nhân.

Từ khóa: u buồng trứng, phẫu thuật nội soi,...

\footnotetext{
${ }^{1}$ Bệnh viện Phụ Sản Thái Bình,

2 Trường Đại hơ Y Hà Nôi

Chịu trách nhiệm chính: Đinh Thị Oanh

Email: oanhdinh1979@gmail.com

Ngày nhận bài: 12.8.2021

Ngày phản biên khoa hoc: 7.10.2021

Ngày duyệt bài: 14.10.2021
}

\section{SUMMARY \\ LAPAROSCOPY FOR OVARIAN TUMORS AT THÁI BİNH PROVINCE HOSPITAL OF OBSTETRICS AND GYNECOLOGY IN 2010 AND 2020 \\ Study Objectives: Consider surgery by} laparoscopy for ovarian tumors at Thái Bình Province Hospital of Obstetrics and Gynecology in 2010 and 2020. Subjects and methods: A retrospective study included 122 patients with ovarian tumors in 2010 and 242 patients in 2020 diagnosed and treated by laparoscopy at Thái Bình Province Hospital of Obstetrics and Gynecology. Result: In 2020, 71,2\% patients were operated by laparoscopy surgery, while $33,3 \%$ patients were surgically treated in 2010 $(p<0.05)$. In 2010, pathological result of $46,7 \%$ patients were serous tumor. In 2020, the rate of mature teratoma was highest $(39.7 \%)$. In 2010 , the rate of laparocopic oophorectomy was highest at the groups had the maximum diameter of the ovarian tumors: $<5 \mathrm{~cm}, \geq 5 \mathrm{~cm}$ but $<10 \mathrm{~cm}$. Whereas in 2020 , the rate of ovarian cystectomy was highest at this groups $(89,8 \%$ and $68.4 \%)$. The group had the maximum diameter of ovarian tumors $>100 \mathrm{~mm}$, $25,0 \%$ patient was performed by ovarian cystectomy. The surgical time with no adhesion or flimy adhesion cases in 2020 was less than time in 2010. There was no complication in during surgery and post-surgery in 2020. Conclusion: Ovarian tumors is one of the most commonly masks in women. Laparoscopic surgery is more and more widely used, bringing the benefits to the patients.

Keywords: ovarian tumor, laparoscopic surgery,...

I. ĐẶT VẤN ĐỀ

U buồng trứng (UBT) là bệnh lý phụ khoa có 